\title{
Limitations of tissue microarrays compared with whole tissue sections in survival analysis
}

\author{
M. HAYSAM KHOUJA ${ }^{1,3}$, MARK BAEKELANDT ${ }^{2}$, AGKHA SARAB ${ }^{3}$, JAHN M. NESLAND ${ }^{1}$ and RUTH HOLM ${ }^{1}$ \\ Departments of ${ }^{1}$ Pathology and ${ }^{2}$ Obstetrics and Gynecology, The Norwegian Radium Hospital, Oslo University Hospital \\ and University of Oslo, Norway; ${ }^{3}$ Department of Pathology, Faculty of Medicine, Aleppo University, Aleppo, Syria
}

Received June 2, 2010; Accepted July 20, 2010

DOI: $10.3892 /$ ol_00000145

\begin{abstract}
Tissue microarray (TMA) is a promising technique in the evaluation of immunohistochemical markers in tumors and may be used as an alternative for whole sections. However, only a few studies have correlated a clinical outcome with both TMA and results obtained from whole sections. This study compared immunostaining for Ki-67 and p16 in TMA ( 3 cores from each specimen) and whole sections of 171 cases of stage III epithelial ovarian cancer with clinical data. A high expression of Ki-67 was identified in 85.0, 85.5, 85.8, 90.5 and $84 \%$ of cores 1, 2 and 3, TMAs and whole tissue sections, respectively. A high p16 expression was found in 36.5, 31.4, $30.3,46.3$ and $31.0 \%$ of cores 1, 2 and 3, TMAs and whole tissue sections, respectively. The high expression of Ki-67 and p16 in whole tissue sections significantly correlated with that of $\mathrm{Ki}-67$ and p16 in core $1(\mathrm{P}<0.0001$ and $\mathrm{P}<0.0001$, respectively), core $2(\mathrm{P}<0.0001$ and $\mathrm{P}<0.0001$, respectively), core 3 $(\mathrm{P}<0.0001$ and $\mathrm{P}<0.0001$, respectively), and TMAs $(\mathrm{P}<0.0001$ and $\mathrm{P}<0.0001$, respectively). In univariate analysis, a high expression of Ki-67 and p16 in two of the cores; TMA and the whole tissue sections were significantly correlated to diseaserelated survival (Ki-67: $\mathrm{P}=0.008,0.012,0.012$ and 0.0001 , respectively, and p16: $\mathrm{P}=0.0007,0.0005,0.0008$ and 0.005 , respectively). However, in the multivariate analysis only Ki-67 on whole tissue sections retained an independent prognostic significance $(\mathrm{P}=0.025)$. We concluded that more studies, with a higher number of cores, are necessary to determine the efficacy of TMA in reflecting the prognostic value of different antibodies. Morever, evaluation of this method is crucial for each type of tumor and each separate antigen. It is also essential to confirm the clinical correlations on the whole sections before investigating the same parameters on TMA.
\end{abstract}

Correspondence to: Dr Ruth Holm, Department of Pathology, The Norwegian Radium Hospital, Oslo University Hospital, Montebello, 0310 Oslo, Norway

E-mail: ruth.holm@oslo-universitetssykehus.no

Key words: tissue microarrays, whole tissue sections, immunohistochemistry, prognosis, Ki-67, p16

\section{Introduction}

Immunohistochemical staining has traditionally been performed on whole tissue sections from paraffin blocks to evaluate the value of proteins as prognostic markers. However, this technique, which requires the processing and staining of hundreds or even thousands of slides, is extremely time-consuming when a large number of tumors or various markers are investigated. In 1998, Kononen et al (1) introduced tissue microarray (TMA) technology which facilitated the retrospective study of a large number of archival formalin-fixed, paraffin-embedded samples. Using this relatively new technology, hundreds of specimens can be inserted into a recipient TMA block that can be tested with different techniques, including immunohistochemical methods. TMA analysis has the added advantage that hundreds of specimens are processed simultaneously using identical conditions. Furthermore, TMA analysis markedly conserves reagents, saves time and greatly decreases the amount of archival tissue required for a particular study, thus preserving tissue for other research or diagnostic needs $(2,3)$. In addition, analysis of serial TMA sections facilitates the identification of associations between multiple markers $(4,5)$. However, the main criticism of TMA is that the amount of tissue analysed using this technique is limited and may not be representative of the whole specimen (6). This may pose a significant problem in malignant epithelial tumors where intratumoral heterogeneity exists $(7,8)$.

Numerous studies have concentrated upon the validation of TMA for different tumors by comparing the immunohistochemical staining results of various core biopsies on TMA with the results of whole section analysis to consider the number of cores required to adequately represent the expression of the antigen (3,6,9-11). Few studies, however, have correlated survival and clinical data with both TMA and the results obtained from whole tissue sections (12-14).

Previously, we identified Ki-67 and p16 (15), using whole tissue sections and immunohistochemistry, in a large series of stage III ovarian cancer and compared the results with clinical information. Using univariate analysis a high expression of Ki-67 ( $\mathrm{P}=0.0001)$ and p16 $(\mathrm{P}=0.005)$ was found to be associated with poor survival. However, in multivariate analysis only a high expression of Ki-67 was significantly associated with shorter survival $(\mathrm{P}=0.025)$ (15). Therefore, TMAs were generated from the 171 paraffin-embedded ovarian 
carcinomas. Each tumor is represented by 3 punches with a diameter of $0.6 \mathrm{~mm}$, and obtained from different sites within the active and representative tumor regions. This study aimed to compare the immunohistochemical expression of $\mathrm{Ki}-67$ and p16 in whole tissue sections and TMAs and establish whether data derived from TMAs can be reliably used for survival analysis in ovarian cancer patients.

\section{Materials and methods}

Patients and samples. Tumor tissue samples from 171 patients with stage III epithelial ovarian cancer, treated in the period from January 1988 to May 1993 at The Norwegian Radium Hospital, were collected during primary surgery. The median age at diagnosis was 54 years (range 21-70). The patients were followed-up until they succumbed to the disease or until December 31st, 2003. Detailed patient information was reported in our previous study (15). The Regional Committee for Medical Research Ethics South of Norway (S-06277a), The Social and Health Directorate (06/3280) and The Data Inspectorate $(06 / 5345)$ approved the study.

TMA construction. A total of 171 ovarian carcinomas were used for TMA construction. Prior to insertion into a TMA block, hematoxylin and eosin (H\&E)-stained sections were created from each tissue donor block to identify the most appropriate (absence of necrosis, poorly differentiated) tumor areas. A total of 3 tissue cylinders with a diameter of $0.6 \mathrm{~mm}$ were removed from selected areas of each tissue donor block using Beecher Instruments (Beecher Instruments, Silver Spring, MD, USA) and placed into a TMA paraffin block. H\&E-stained sections from the TMA blocks were generated for histological evaluation.

Immunohistochemistry. Whole tissue sections and TMA slides were immunostained using the Dako EnVision ${ }^{\mathrm{TM}}+$ System, Peroxidase (DAB) (K4007, Dako Corporation, CA, USA) and Dako Autostainer, as previously described (15). Briefly, after deparaffinization, the sections were incubated with monoclonal antibodies against p16 (clone 16P04, diluted 1:200, 1 $\mu \mathrm{g}$ IgG1/ml) from NeoMarkers, Inc., CA, USA and Ki-67 (clone Ki-S5, 1:50, $0.9 \mu \mathrm{g} \mathrm{IgG1/ml)} \mathrm{from} \mathrm{Dako} \mathrm{A/S,} \mathrm{Glostrup,}$ Denmark, for $30 \mathrm{~min}$ at room temperature. The sections were then incubated with peroxidase-labeled polymer conjugated to goat anti-mouse for $30 \mathrm{~min}$ and 3'3-diaminobenzidine tetrahydrochloride (DAB) for $10 \mathrm{~min}$. Positive controls (cervical carcinomas for p16 and tonsils for $\mathrm{Ki}-67$ ) were included in the series. Negative controls included substitution of the monoclonal antibody with mouse myeloma protein of the same subclass and concentration as the monoclonal antibody. The controls yielded satisfactory results. Only distinct nuclear staining was considered to be positive. A total of 4 semiquantitative classes were used to describe the number of positively-stained tumor cells: none, $<10 \%$ positive; $10-50 \%$ positive and $>50 \%$ positive. Two independent investigators (M.H.K. and R.H.) scored the whole tissue sections and TMA slides with no knowledge of the clinical data. Conflicting results were reviewed until a final agreement was achieved. Protein levels were classified as high when $\geq 10 \%$ of the cells were positive for $\mathrm{Ki}-67$ and $>50 \%$ of the cells were positive for p16. The levels were classified based on our previous publication (15). This study showed the results for each of the three tissue cores (1, 2 and 3), TMAs (a tumor was considered to be a high expression of $\mathrm{Ki}-67$ or p16 if at least one of the three tissue cores was scored as a high expression) and the whole tissue sections.

Statistical analysis. Differences in proportions were evaluated by the Chi-square or Fisher's exact test as required. The Kaplan-Meier method was used to calculate the disease-free and corrected survival rates (16). The long-rank test was used for univariate analysis and a Cox proportional hazards regression model was used for multivariate evaluation of the survival rates (17). A backward stepwise selection procedure was used for the multivariate analysis. The hazard proportionality was verified by computing the $\log$ - log against time. Statistical analysis was performed using the SPSS 15.0 software package (SPSS, Chicago, IL, USA). P $<0.05$ was regarded as statistically significant.

\section{Results}

Table I shows a summary of the immunohistochemical results for Ki-67 and p16 in the three cores, TMAs and whole tissue sections. Only 88/1026 cores (8.6\%) were missing, including $39 / 513(7.6 \%)$ for $\mathrm{Ki}-67$ and $49 / 512(9.6 \%)$ for p16, resulting in $2 / 171(1.2 \%)$ cases for Ki-67 and 7/171 (4.1\%) cases for p16 that were not noted in the TMAs. Excluding the missing tissue cores, a high expression of $\mathrm{Ki}-67$ was identified in $85.0 \%$ of core $1,85.5 \%$ of core $2,85.8 \%$ of core $3,90.5 \%$ of TMAs and $84 \%$ of whole tissue sections. For p16, a high expression was found in $36.5 \%$ of core $1,31.4 \%$ of core $2,30.3 \%$ of core $3,46.3 \%$ of TMAs and $31.0 \%$ of whole tissue sections. The high expression of $\mathrm{Ki}-67$ and p16 in whole tissue sections significantly correlated with a high expression of Ki-67 and p16 in core $1(\mathrm{P}<0.0001$ and $\mathrm{P}<0.0001$, respectively), core 2 $(\mathrm{P}<0.0001$ and $\mathrm{P}<0.0001$, respectively), core $3(\mathrm{P}<0.0001$ and $\mathrm{P}<0.0001$, respectively) and TMAs $(\mathrm{P}<0.0001$ and $\mathrm{P}<0.0001$, respectively). Examples of the high expression for Ki-67 and p16 are shown for a core in TMA and whole sections (Fig. 1).

Previously, we found, in the same patient population, that in the univariate analysis, FIGO substage $(\mathrm{P}=0.0002)$, presence of ascites $(\mathrm{P}=0.0012)$, presence of residual disease after surgery $(\mathrm{P}<0.0001)$, degree of differentiation $(\mathrm{P}=0.0001)$, Silverberg histopathological grade (grade 1 vs. grade $2 / 3$ ) $(\mathrm{P}=0.0019)$ and age $(\mathrm{P}=0.045)$ were correlated to diseaserelated survival (15). In univariate analysis, high expression levels for $\mathrm{Ki}-67$ on core $2(\mathrm{P}=0.008)$, core $3(\mathrm{P}=0.012)$, TMA $(\mathrm{P}=0.012)$ and whole tissue sections $(\mathrm{P}=0.0001)$ were significantly correlated to disease-related survival, whereas, Ki-67 expression on core 1 was not significantly correlated to disease-related survival $(\mathrm{P}=0.054)$. High expression levels for p16 on core $1(\mathrm{P}=0.0007)$, core $2(\mathrm{P}=0.0005)$, TMA $(\mathrm{P}=0.0008)$ and whole tissue sections $(\mathrm{P}=0.005)$ were correlated to disease-related survival. No significant association was observed between p16 expression on core 3 and diseaserelated survival $(\mathrm{P}=0.055)$.

The variables that reached significance in the univariate survival analysis were incorporated in a multivariate analysis, with disease-related survival used as the end point. In this 
Table I. Summary of immunohistochemical analysis.

\begin{tabular}{|c|c|c|c|c|c|c|c|c|c|c|}
\hline & \multicolumn{5}{|c|}{ Ki67 } & \multicolumn{5}{|c|}{ p16 } \\
\hline & $\mathrm{C} 1$ & $\mathrm{C} 2$ & $\mathrm{C} 3$ & TMA & Whole & $\mathrm{C} 1$ & $\mathrm{C} 2$ & $\mathrm{C} 3$ & TMA & Whole \\
\hline Low & $\begin{array}{c}24 \\
(14.0)^{\mathrm{a}}\end{array}$ & $\begin{array}{c}23 \\
(13.5)\end{array}$ & $\begin{array}{c}22 \\
(12.9)\end{array}$ & $\begin{array}{c}16 \\
(9.4)\end{array}$ & $\begin{array}{c}27 \\
(16.0)\end{array}$ & $\begin{array}{c}99 \\
(57.9)\end{array}$ & $\begin{array}{c}107 \\
(62.6)\end{array}$ & $\begin{array}{c}106 \\
(61.9)\end{array}$ & $\begin{array}{c}88 \\
(51.5)\end{array}$ & $\begin{array}{c}118 \\
(69.0)\end{array}$ \\
\hline High & $\begin{array}{c}136 \\
(79.5)\end{array}$ & $\begin{array}{c}136 \\
(79.5)\end{array}$ & $\begin{array}{c}133 \\
(77.8)\end{array}$ & $\begin{array}{c}153 \\
(89.5)\end{array}$ & $\begin{array}{c}144 \\
(84.0)\end{array}$ & $\begin{array}{c}57 \\
(33.3)\end{array}$ & $\begin{array}{c}49 \\
(28.6)\end{array}$ & $\begin{array}{c}46 \\
(26.9)\end{array}$ & $\begin{array}{c}76 \\
(44.4)\end{array}$ & $\begin{array}{c}53 \\
(31.0)\end{array}$ \\
\hline Missing & $\begin{array}{c}11 \\
(6.4)\end{array}$ & $\begin{array}{c}12 \\
(7.0)\end{array}$ & $\begin{array}{c}16 \\
(9.4)\end{array}$ & $\begin{array}{c}2 \\
(1.2)\end{array}$ & 0 & $\begin{array}{c}15 \\
(8.8)\end{array}$ & $\begin{array}{c}15 \\
(8.8)\end{array}$ & $\begin{array}{c}19 \\
(11.1)\end{array}$ & $\begin{array}{c}7 \\
(4.1)\end{array}$ & 0 \\
\hline Total & 171 & 171 & 171 & 171 & 171 & 171 & 171 & 171 & 171 & 171 \\
\hline
\end{tabular}

C, core; TMA, tissue microarray (in the TMAs a tumor was considered to be a high expression of Ki-67 or p16 if at least one tissue core was scored as high expression); Whole, whole tissue section; ${ }^{\mathrm{a}}(\%)$.

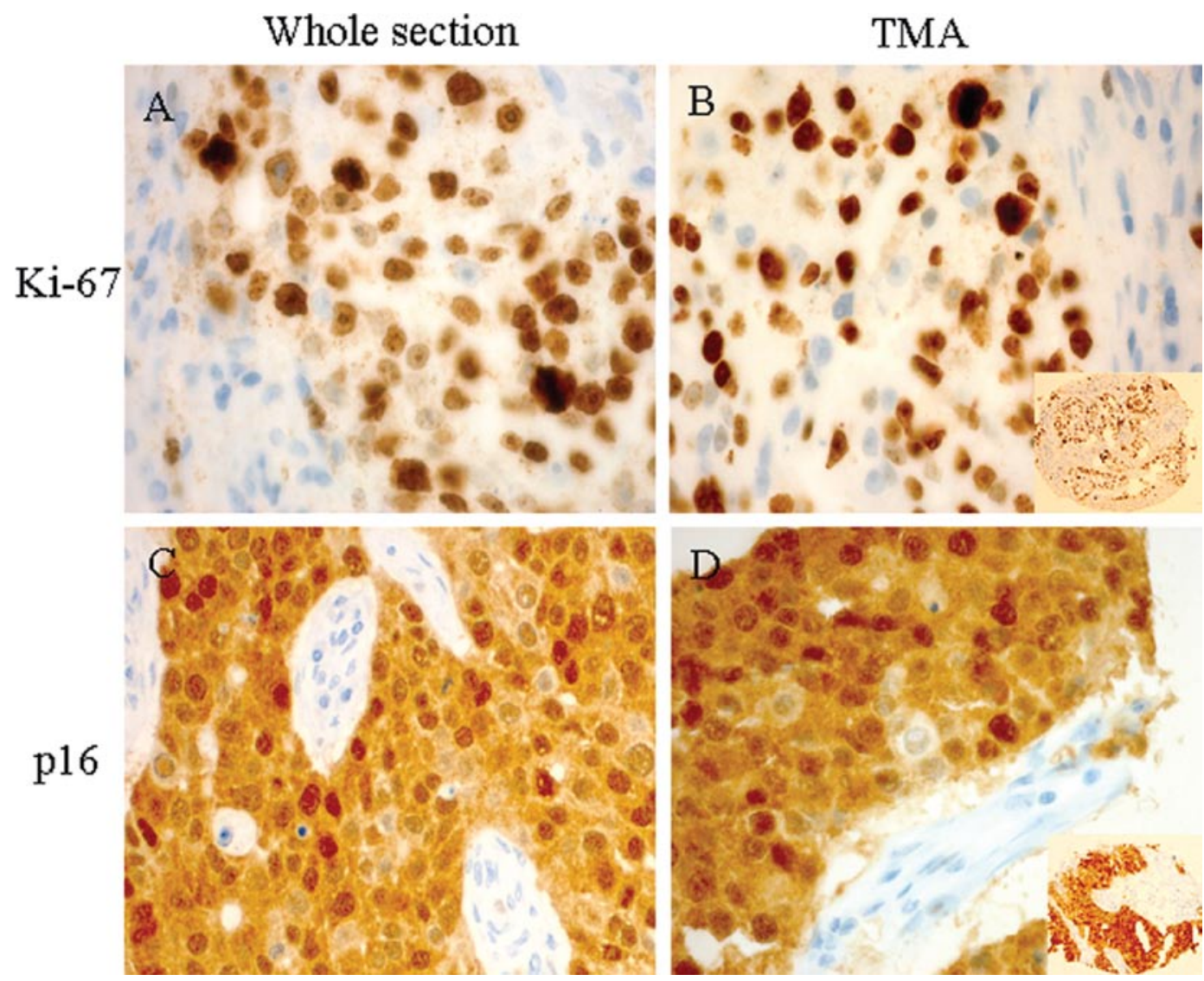

Figure 1. Immunohistochemical staining of Ki-67 on (A) whole section and (B) TMA and p16 on (C) whole section and (D) TMA. Insets show tissue cores containing tumor and stromal areas.

study, only residual disease $(\mathrm{P}=0.0003)$, differentiation grade $(\mathrm{P}=0.012)$ and $\mathrm{Ki}-67$ on whole tissue sections $(\mathrm{P}=0.025)$ retained independent prognostic significance, with a high expression of Ki-67 indicating shorter disease-related survival (15). Prognostic significance was not achieved in Ki-67 expression on the three individual cores and the TMAs. Furthermore, prognostic significance was not achieved in the multivariate analysis in p16 on whole tissue sections, the three individual cores and the TMAs.

\section{Discussion}

TMA is proving to be a user-friendly technique in the evaluation of immunohistochemical markers in tumors and may be an alternative for whole sections especially in studies that investigate a large number of cases. Numerous studies have used this technology to examine the associations between molecular changes and clinicopathological characteristics of tumors $(4,15,18)$. However, only a few studies have correlated 
survival and clinical data with both TMA and results obtained from whole sections to establish whether data from TMAs can be reliably used for clinicopathological correlations and survival analysis $(12,14)$. The majority of studies investigated the ability of TMA to represent whole sections in immunohistochemical studies of certain antigens as well as the optimal number of TMA cores needed to achieve acceptable representation of the specimens $(6,10,19-21)$. Our results showed that even one $0.6 \mathrm{~mm}$ TMA core represented whole sections as significantly as the score of all three TMA cores. In agreement with our results, a study on breast cancer (3) concluded that one or two TMA cores per case result in outcomes that are $95 \%$ similar to those achieved using conventional tissue sections. However, the majority of validation studies have found that analysis of two to three $0.6 \mathrm{~mm}$ cores produces higher concordance rates than the use of one core; the percentage of missing cores is also reduced (3,6,22-24). Jourdan et al (9) analyzed eight $(0.6 \mathrm{~mm})$ cores per tumor in colorectal carcinomas and concluded that compared with one or two cores, three cores significantly increase the concordance rate with the whole sections, and decrease the risk of missing cases. However, another study on colorectal adenoma (19) indicated that, due to the heterogeneous staining pattern, four $(0.6 \mathrm{~mm})$ cores are required to reliably assess the expression levels of Ki-67. Furthermore, other studies suggested that even two cores, but with a larger diameter $(1 \mathrm{~mm})$, provide sufficient information to achieve results similar to those obtained from whole sections (11). The discrepancy in the number of cores required to obtain acceptable representation of the specimens may be due to variation of the heterogeneity of the antigens in the tumors tested.

The missing cores in our study comprised $8.6 \%$ of the entire number of cores. This result was acceptable considering the large number of cores, and the comparison of missing core percentages of other similar studies; these core percentages deteriorated from 6.6 to $17 \%(11,19,20)$.

Considering the previous results, our study was also concerned with the reliability of the TMA immunohistochemical results of certain antibodies as prognostic markers. Our results showed a significant correlation of high expression levels for Ki-67 and p16 in TMA and whole tissue sections to disease-related survival in univariate analyses. However, prognostic significance was not achieved when the same variables were incorporated in a multivariate analysis. In this case, only certain clinical parameters retained independent prognostic significance, and a high expression of Ki-67 and p16 was not significant on each of the three individual cores and the TMAs. In contrast, in the multivariate analysis whole tissue sections in Ki-67 expression retained independent prognostic significance (15). A review of the literature showed that various studies investigated the clinico-immunologic correlations using TMAs (25). However, only a few studies have correlated survival and clinical data with both TMA and results obtained from whole sections to establish whether data from TMAs can be reliably used for clinicopathological correlations and survival analysis $(12,14)$. In concordance with our results, a study of 199 patients with prostatic carcinoma (13) revealed that the prognostic value of p53 and bcl-2 were not confirmed using TMA technology in contrast to radical prostatectomy sections. In this study, two cores of $0.6 \mathrm{~mm}$ from each repre- sentative area of each case were selected. It was found that the value of TMAs in the search for prognostic markers may be limited to biomarkers with diffuse expression and not focally clustered biomarkers such as p53 and bcl-2. Another study on breast carcinomas (14) proved that an analysis of three antibodies on four cores per tumor yielded more significant associations with tumor-specific survival than large section analyses. By contrast, a study on bladder carcinoma, using four replica TMAs of $0.6 \mathrm{~mm}$, showed a correlation between the Ki-67 LI (labeling index) and tumor stage or prognoses that highly reproduce whole section data (12). These studies indicate that the prognostic value of TMA compared to whole sections may depend on the type of cancers, number of cores and the antigen investigated.

In conclusion, the question regarding to what extent TMAs are able to represent whole sections is currently being investigated by a growing number of studies that have proved the reliability of this technique. However, a crucial point is whether TMA is able to reproduce clinicopatholological correlations that exist on whole section analyses. Additionally, the number of cores required to achieve this particular purpose should be investigated. Although TMA may have advantages, such as being cost-effective and saving time and tissues, our results indicate that further studies, with the use of a larger number of cores are necessary to determine the efficacy of TMA to reflect the prognostic value of different antibodies. Moreover, this method should be evaluated for each type of tumor and each separate antigen. Confirmation of the clinical associations on whole sections prior to investigating the same parameters on TMAs should also be obtained.

\section{Acknowledgements}

We thank Ellen Hellesylt and Mette Førsund for their excellent technical assistance. This study was supported in part by grants from The Norwegian Cancer Society and Inger and John Fredriksen Foundation for Ovarian Cancer Research.

\section{References}

1. Kononen J, Bubendorf L, Kallioniemi A, Barlund M, Schraml P, Leighton S, Torhorst J, Mihatsch MJ, Sauter G and Kallioniemi OP: Tissue microarrays for high-throughput molecular profiling of tumor specimens. Nat Med 4: 844-847, 1998.

2. Mills SE, Fechner RE, Frierson HF, Kempson RL, Wick MR, Dehner LP, Swanson PE and Humphrey PA: Guardians of the wax ... and the patient. Am J Clin Pathol 104: 365-367, 1995.

3. Camp RL, Charette LA and Rimm DL: Validation of tissue microarray technology in breast carcinoma. Lab Invest 80: 1943-1949, 2000.

4. Tolgay OI, Dolled-Filhart M, D'Aquila TG, Camp RL and Rimm DL: Tissue microarray-based studies of patients with lymph node negative breast carcinoma show that met expression is associated with worse outcome but is not correlated with epidermal growth factor family receptors. Cancer 97: 1841-1848, 2003.

5. Korsching E, Packeisen J, Agelopoulos K, Eisenacher M, Voss R, Isola J, van Diest PJ, Brandt B, Boecker W and Buerger H: Cytogenetic alterations and cytokeratin expression patterns in breast cancer: integrating a new model of breast differentiation into cytogenetic pathways of breast carcinogenesis. Lab Invest 82: 1525-1533, 2002.

6. Griffin MC, Robinson RA and Trask DK: Validation of tissue microarrays using p53 immunohistochemical studies of squamous cell carcinoma of the larynx. Mod Pathol 16: 1181-1188, 2003. 
7. Kuwabara S, Ajioka Y, Watanabe H, Hitomi J, Nishikura K and Hatakeyama K: Heterogeneity of p53 mutational status in esophageal squamous cell carcinoma. Jpn J Cancer Res 89: 405-410, 1998

8. Baisse B, Bouzourene H, Saraga EP, Bosman FT and Benhattar J: Intratumor genetic heterogeneity in advanced human colorectal adenocarcinoma. Int J Cancer 93: 346-352, 2001.

9. Jourdan F, Sebbagh N, Comperat E, Mourra N, Flahault A, Olschwang S, Duval A, Hamelin R and Flejou JF: Tissue microarray technology: validation in colorectal carcinoma and analysis of p53, hMLH1, and hMSH2 immunohistochemical expression. Virchows Arch 443: 115-121, 2003.

10. Gomaa W, Ke Y, Fujii $\mathrm{H}$ and Helliwell T: Tissue microarray of head and neck squamous carcinoma: validation of the methodology for the study of cutaneous fatty acid-binding protein, vascular endothelial growth factor, involucrin and Ki-67. Virchows Arch 447: 701-709, 2005.

11. Rosen DG, Huang X, Deavers MT, Malpica A, Silva EG and Liu J: Validation of tissue microarray technology in ovarian carcinoma. Mod Pathol 17: 790-797, 2004.

12. Nocito A, Bubendorf L, Tinner EM, et al: Microarrays of bladder cancer tissue are highly representative of proliferation index and histological grade. J Pathol 194: 349-357, 2001.

13. Merseburger AS, Kuczyk MA, Serth J, et al: Limitations of tissue microarrays in the evaluation of focal alterations of bcl-2 and p53 in whole mount derived prostate tissues. Oncol Rep 10: 223-228, 2003.

14. Torhorst J, Bucher C, Kononen J, Haas P, Zuber M, Kochli OR, Mross F, Dieterich H, Moch H, Mihatsch M, Kallioniemi OP and Sauter G: Tissue microarrays for rapid linking of molecular changes to clinical endpoints. Am J Pathol 159: 2249-2256, 2001 .

15. Khouja MH, Baekelandt M, Nesland JM and Holm R: The clinical importance of $\mathrm{Ki}-67, \mathrm{p} 16, \mathrm{p} 14$, and p57 expression in patients with advanced ovarian carcinoma. Int $\mathrm{J}$ Gynecol Pathol 26: 418-425, 2007.
16. Kaplan EL and Meier P: Nonparametric estimation from incomplete observation. J Am Stat Assoc 53: 457-481, 1958.

17. Cox DR: Regression models and life tables. J R Stat Soc B 34 187-220, 1972.

18. Sapino A, Marchio C, Senetta R, Castellano I, Macri L, Cassoni P, Ghisolfi G, Cerrato M, D'Ambrosio E and Bussolati G: Routine assessment of prognostic factors in breast cancer using a multicore tissue microarray procedure. Virchows Arch 449: 288-296, 2006

19. Su Y, Shrubsole MJ, Ness RM, Cai Q, Kataoka N, Washington K and Zheng W: Immunohistochemical expressions of $\mathrm{Ki}-67$, cyclin D1, beta-catenin, cyclooxygenase-2, and epidermal growth factor receptor in human colorectal adenoma: a validation study of tissue microarrays. Cancer Epidemiol Biomarkers Prev 15: 1719-1726, 2006.

20. Leversha MA, Fielding P, Watson S, Gosney JR and Field JK: Expression of p53, pRB, and p16 in lung tumours: a validation study on tissue microarrays. J Pathol 200: 610-619, 2003.

21. Tawfik El-Mansi M and Williams AR: Validation of tissue microarray technology using cervical adenocarcinoma and its precursors as a model system. Int $\mathbf{J}$ Gynecol Cancer 16: 1225-1233, 2006

22. Kallioniemi OP, Wagner U, Kononen J and Sauter G: Tissue microarray technology for high-throughput molecular profiling of cancer. Hum Mol Genet 10: 657-662, 2001.

23. Fernebro E, Dictor M, Bendahl PO, Ferno $M$ and Nilbert $M$ : Evaluation of the tissue microarray technique for immunohistochemical analysis in rectal cancer. Arch Pathol Lab Med 126: 702-705, 2002.

24. Fons G, Hasibuan SM, van der Velden J and ten Kate FJ: Validation of tissue microarray technology in endometrioid cancer of the endometrium. J Clin Pathol 60: 500-503, 2007.

25. Zerkowski MP, Camp RL, Burtness BA, Rimm DL and Chung GG: Quantitative analysis of breast cancer tissue microarrays shows high cox-2 expression is associated with poor outcome. Cancer Invest 25: 19-26, 2007. 